\title{
Primary thrombolysis for free flap surgery in head and neck reconstruction: a case report and review
}

\author{
Steven Liben Zhang, Hui Wen Ng \\ Section of Plastic, Reconstructive and Aesthetic Surgery, Department of General Surgery, Tan Tock Seng Hospital, Singapore
}

The use of free flaps is an essential and reliable method of reconstruction in complex head and neck defects. Flap failure remains the most feared complication, the most common cause being pedicle thrombosis. Among other measures, thrombolysis is useful when manual thrombectomy has failed to restore flap perfusion, in the setting of late or established thrombosis, or in arterial thrombosis with distal clot propagation. We report a case of pedicle arterial thrombosis with distal clot propagation which occurred during reconstruction of a maxillectomy defect, and was successfully treated with thrombolysis using recombinant tissue plasminogen activator. We also review the literature regarding the use of thrombolysis in free flap surgery, and propose an algorithm for the salvage of free flaps in head and neck reconstruction.

Keywords Thrombolytic therapy / Free tissue flaps / Reconstructive surgical procedures / Surgery, plastic / Fibrinolytic agents
Correspondence: Steven Liben Zhang Section of Plastic, Reconstructive and Aesthetic Surgery, Department of General Surgery, Tan Tock Seng Hospital, 11 Jln Tan Tock Seng, Singapore 308433, Singapore Tel: +65-9090-5401

E-mail: zlb.steven@gmail.com

Received: January 16, $2021 \bullet$ Revised: May 5, $2021 \bullet$ Accepted: May 27, 2021

pISSN: 2234-6163 • elSSN: 2234-6171 • https://doi.org/10.5999/aps.2021.00171 • Arch Plast Surg 2021;48:511-517

\section{INTRODUCTION}

Microvascular free tissue transfer has become an essential tool in the reconstruction of complex head and neck defects following cancer extirpation [1]. Flap failure remains the most feared complication, with an incidence of about $2 \%$ to $5 \%$ [2]. The most common cause is anastomotic complications, which occur most frequently in the early postoperative period and necessitate urgent flap re-exploration [3]. Re-exploration rates range from $6 \%$ to $14 \%$, the most common cause being pedicle thrombosis $[1,2]$.

Management of suspected flap compromise involves prompt re-exploration and addressing the underlying cause-revision of anastomoses if it is a technical issue, repositioning or untwisting of vessels if there is kinking or compression, evacuation of compressing hematomas, or use of vein grafts if there is excessive tension [4]. If the cause is pedicle thrombosis, intraluminal thrombi should be removed, by milking the vessels or with the aid of Fogarty catheters (i.e., Fogarty thrombectomy) [1]. When such measures fail to restore flow, or in the setting of extensive and established thrombosis, thrombolysis should be considered $[1,5]$, and has been shown to improve salvage rates [5].

Occasionally, pedicle thrombosis may occur during the primary surgery itself as opposed to the postoperative period. This may be due to technical issues, or predisposing "vasculopathy" factors such as smoking, diabetes mellitus, and cancer. While there have been numerous reviews on the use of thrombolysis in flap re-exploration, a review of the literature did not reveal any published reports on its use in primary surgery. We report a case of pedicle arterial thrombosis with distal clot propagation which occurred during free flap reconstruction of a maxillecto- 
my defect, and was successfully treated with thrombolysis using recombinant tissue plasminogen activator (rTPA). We also review the literature regarding the use of thrombolysis in free flap surgery, and propose an algorithm for the salvage of free flaps in head and neck reconstruction. Informed consent was obtained from the patient for the use of his imaging records in this case report.

\section{CASE}

A 73-year-old man with a 20 pack-year history of cigarette smoking presented with a painless lump over the palate (Fig. 1). Biopsy confirmed a diagnosis of carcinoma with clear cell features. Staging scans did not reveal evidence of nodal involvement or distant metastases. Following right subtotal maxillectomy and selective neck dissection (Fig. 2), reconstruction was performed with a free anterolateral thigh musculocutaneous flap (Fig. 3).

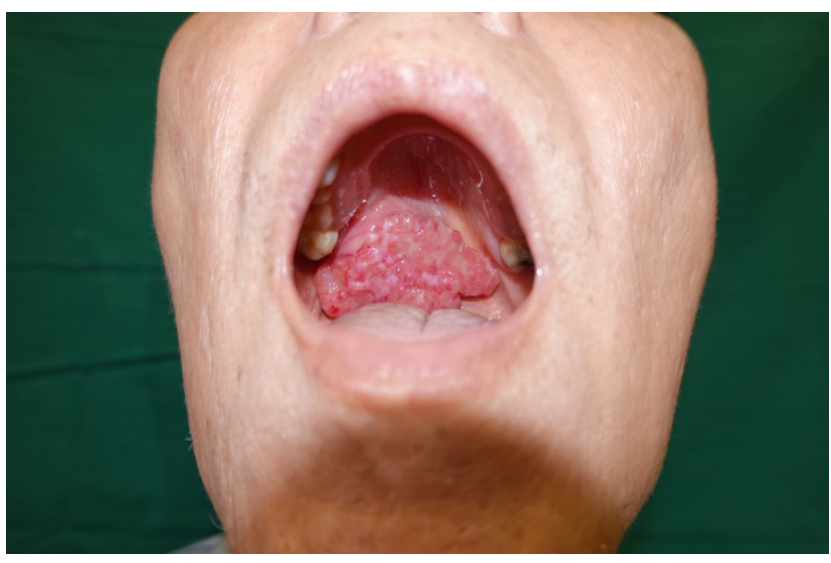

Fig. 1. Clinical photograph of palatal tumor.

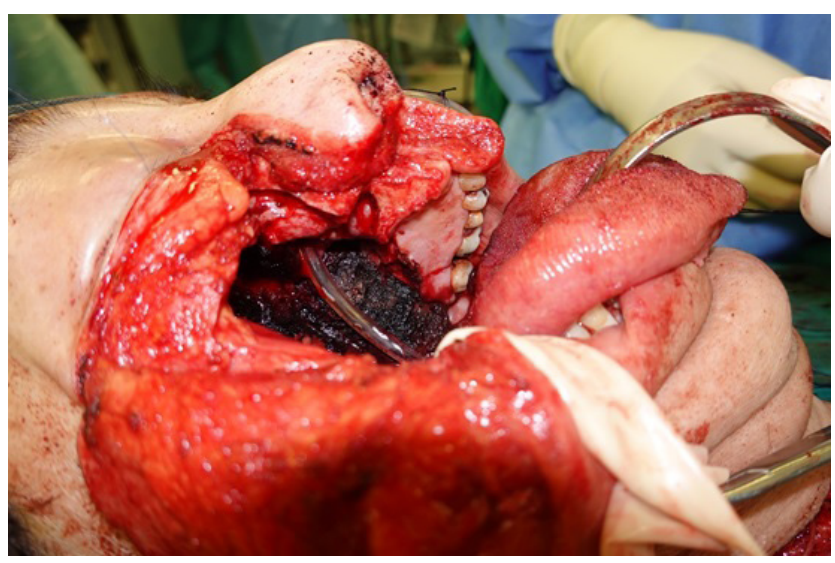

Fig. 2. Post-maxillectomy defect.
End-to-end microvascular anastomosis was performed with Ethilon 9-0 sutures. The flap artery and two veins (descending branch of the lateral circumflex femoral artery and paired venae comitantes) were anastomosed to the right superior thyroid artery, a branch of the internal jugular vein, and a branch of the external jugular vein, respectively (Fig. 4). The flap was bleeding well after anastomosis, and inset was performed.

Thirty minutes later, bleeding from the flap was noted to have stopped, and inspection revealed an intraluminal thrombus at the arterial anastomosis. Milking of the thrombus was attempted but there was no improvement in flap perfusion. The flap and all anastomoses were taken down, and thrombi were noted distally within the branches of the flap artery (muscle branches and perforators). The vessels were milked from as distally as is possible along the main pedicle. However, attempts at flushing with heparinized saline were still met with high resistance, indicating that there was thrombosis further distally where muscle and musculocutaneous perforators entered the flap. Hence a de-

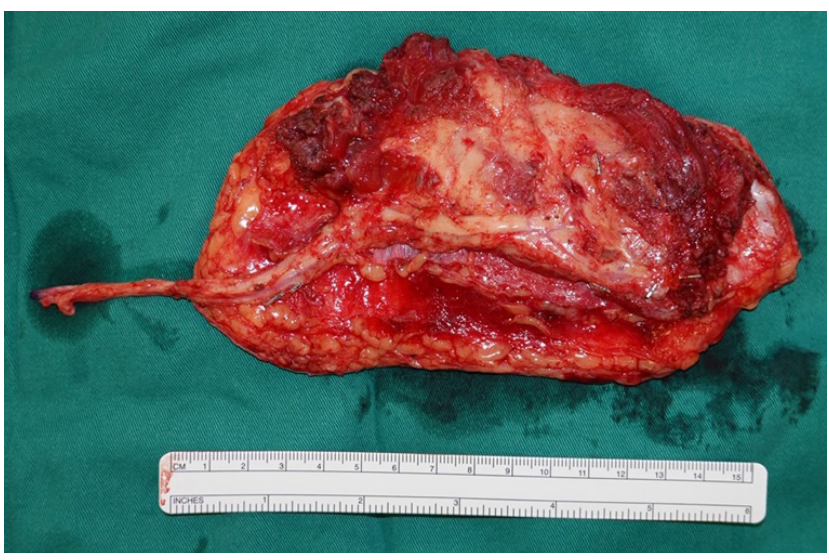

Fig. 3. Free anterolateral thigh musculocutaneous flap.

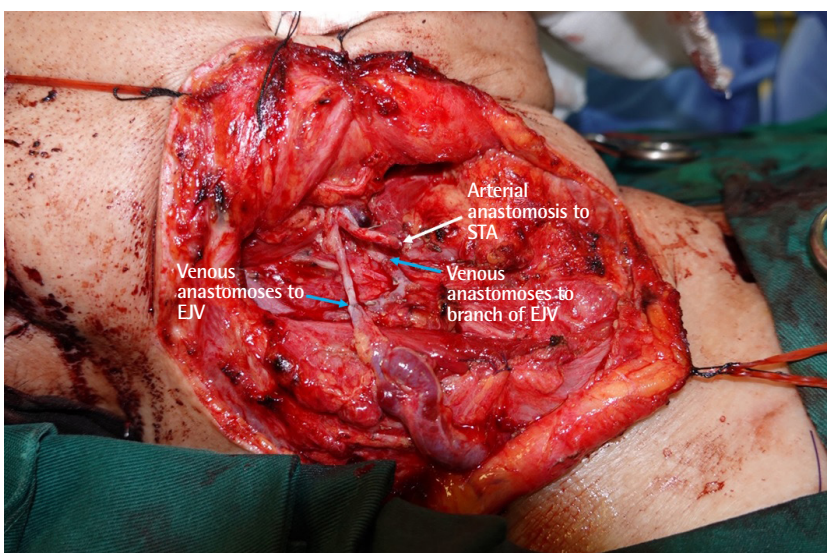

Fig. 4. Microvascular anastomosis (blue arrows are venous anastomoses and white arrow is arterial anastomosis). EJV, external jugular vein; IJV, internal jugular vein; STA, superior thyroid artery. 
cision was made for flap thrombolysis.

Both veins were clamped, and $10 \mathrm{mg}$ of rTPA was injected through the artery, which was then clamped as well (Fig. 5). After 10 minutes, all clamps were released, and $30 \mathrm{~mL}$ of heparinized saline was injected through the artery to flush out the rTPA. This process was repeated, providing a total of $20 \mathrm{mg}$ of rTPA

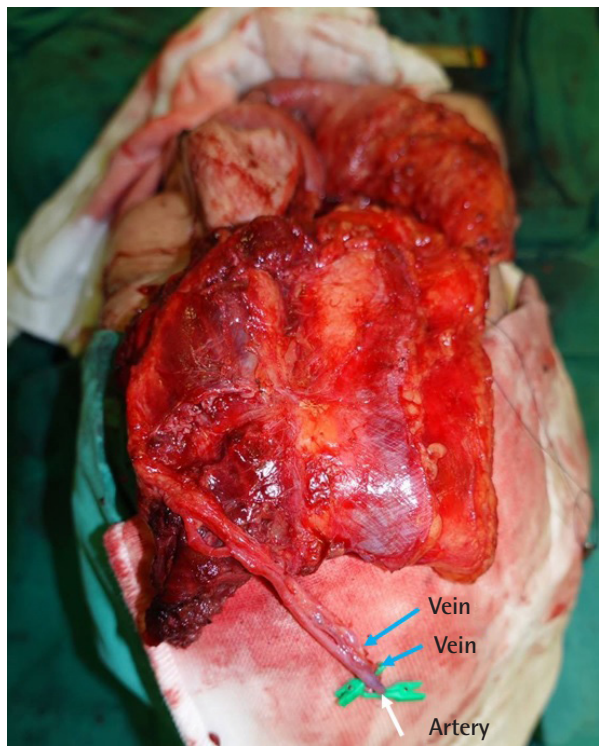

Fig. 5. Flap following instillation of recombinant tissue plasminogen activator.

Table 1. Characteristics and findings of studies on flap thrombolysis

\begin{tabular}{|c|c|c|c|c|c|c|c|}
\hline Author (year) & Dose of rTPA & Indication & $\begin{array}{l}\text { Efficacy (with } \\
\text { thrombolysis vs. } \\
\text { without) }\end{array}$ & $\begin{array}{l}\text { No. of free flaps/ } \\
\text { patients }\end{array}$ & $\begin{array}{l}\text { No. of re- } \\
\text { explorations }\end{array}$ & $\begin{array}{l}\text { No. of } \\
\text { thrombosis }\end{array}$ & $\begin{array}{l}\text { No. of } \\
\text { thrombolysis }\end{array}$ \\
\hline Bui et al. (2007) [1] & $\begin{array}{l}\text { 5-20 mg (dilution } \\
1 \mathrm{mg} / \mathrm{mL} \text { ) (leave in for } \\
10-20 \mathrm{~min} \text { ) }\end{array}$ & $\begin{array}{l}\text { 1. Late thrombosis (established } \\
\text { clot) } \\
\text { 2. Poor venous return after re- } \\
\text { establishment of arterial inflow }\end{array}$ & $\begin{array}{l}65 \% \text { vs. } 61 \% \\
\quad(P>0.05)\end{array}$ & $\begin{array}{l}\text { 1,193 Free flaps/ } \\
1,179 \text { patients }\end{array}$ & 71 & 38 & 20 \\
\hline Casey et al. (2007) [3] & $\begin{array}{l}2 \mathrm{mg} \text { (dilution } 1 \mathrm{mg} / \mathrm{mL} \text { ) } \\
\text { over } 1 \mathrm{~min}\end{array}$ & Extensive venous thrombosis & $\begin{array}{l}\text { NA (11/11, but no } \\
\text { comparison) }\end{array}$ & 122 Free flaps & Not indicated & 12 & 11 \\
\hline Rinker et al. (2007) [5] & $\begin{array}{l}2.5 \mathrm{mg} \text { (if not restored } \\
\text { after } 10-15 \mathrm{~min}, \\
\text { another } 2.5 \mathrm{mg} \text { ) }\end{array}$ & $\begin{array}{l}\text { Failure of mechanical } \\
\text { thrombectomy to restore flow }\end{array}$ & $\begin{array}{l}67 \% \text { vs. } 29 \% \\
\quad(P=0.17)\end{array}$ & $\begin{array}{l}275 \text { Free flaps/ } \\
259 \text { patients }\end{array}$ & 27 & 22 & 15 \\
\hline $\begin{array}{l}\text { Panchapakesan et al. } \\
\text { (2003) [7] }\end{array}$ & NA (urokinase) & $\begin{array}{l}\text { Failure to establish satisfactory } \\
\text { venous outflow }\end{array}$ & $\begin{array}{c}30 \% \text { vs. } 54 \% \\
(P>0.05)\end{array}$ & 590 Free flaps & 71 & 44 & 20 \\
\hline Bonde et al. (2004) [8] & $\begin{array}{l}50 \mathrm{mg} \text { over } 15 \mathrm{~min} \text { (then } \\
50 \mathrm{mg} \text { systemic over } \\
45 \mathrm{~min} \text { ) }\end{array}$ & $\begin{array}{l}\text { Failure of mechanical } \\
\text { thrombectomy to restore venous } \\
\text { flow }\end{array}$ & $\begin{array}{l}\text { NA (2/2, but no } \\
\text { comparison) }\end{array}$ & 2 Free flaps & 2 & 2 & 2 \\
\hline Yii et al. (2001) [9] & $15 \mathrm{mg}$ & Late thrombosis & $\begin{array}{l}75 \% \text { vs. } 67 \% \\
(P>0.05)\end{array}$ & 1,733 Free flaps & 55 & 41 & 8 \\
\hline Serletti et al. (1998) [10] & NA (urokinase) & Venous thrombosis & $\begin{array}{l}\text { NA (5/5, but no } \\
\text { comparison) }\end{array}$ & $>600$ Free flaps & Not indicated & 8 & 5 \\
\hline Chang et al. (2011) [11] & $2.5 \mathrm{mg}$ (average) & $\begin{array}{l}\text { 1. Post-arterial thrombectomy with } \\
\text { distal clot propagation } \\
\text { 2. Post-arterial and venous } \\
\text { thrombectomy, following arterial } \\
\text { revision } \\
\text { 3. Post-venous thrombectomy }\end{array}$ & $\begin{array}{l}84.8 \% \text { vs. } 92.7 \% \\
\quad(P>0.05)\end{array}$ & Not indicated & Not indicated & 74 & 33 \\
\hline
\end{tabular}

rTPA, recombinant tissue plasminogen activator; NA, not applicable. instillation. Five thousand units of intravenous heparin were given. Microvascular anastomosis was then repeated, and the flap was noted to be bleeding well. Flap inset was completed and the skin was closed over suction drains.

Postoperatively, the flap was monitored as per routine protocol and remained viable. The patient developed mild right perior-

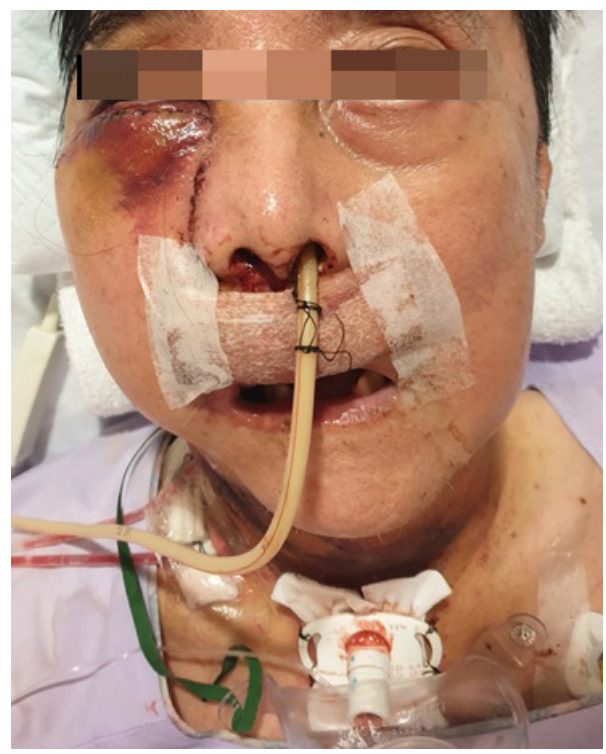

Fig. 6. Mild right periorbital hematoma. 


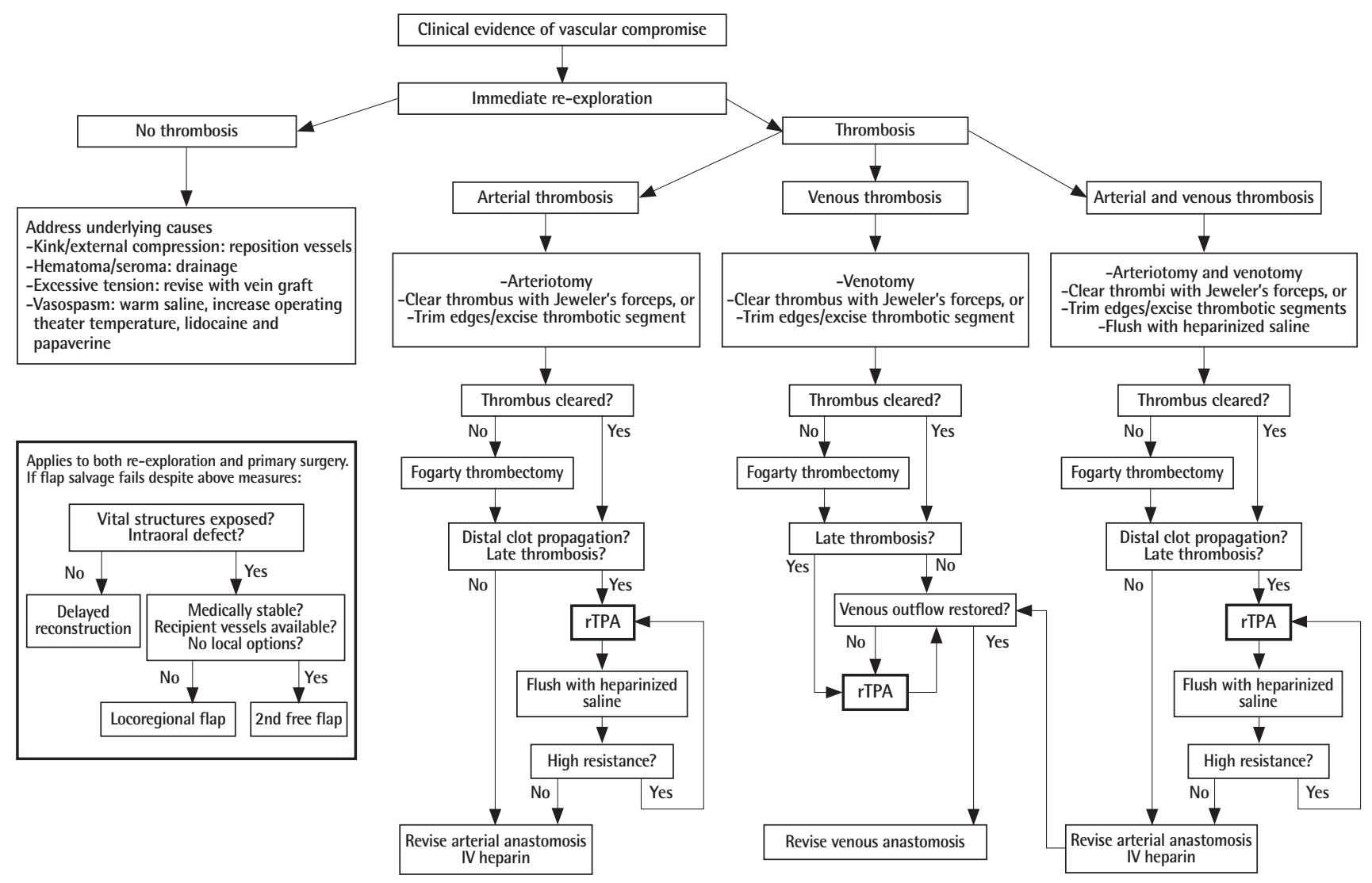

Fig. 7. Proposed algorithm for flap salvage in head and neck reconstruction. rTPA, recombinant tissue plasminogen activator; IV, intravenous.

bital bruising from postoperative day 1 (Fig. 6), which was selflimiting and resolved. He was discharged and remained well on follow-up.

\section{DISCUSSION}

The use of thrombolysis in free flap surgery is not new. Following successful reports in animal studies, Lipton and Jupiter [6] first described the use of streptokinase to salvage a free osteocutaneous fibula flap with venous pedicle thrombosis. Since then, the use of thrombolytic agents has been published in other studies, and become part of routine flap salvage protocol in numerous centers (Table 1). However, it has only been described in reexploration, with no reports of its use in primary surgery to date. Although the principles of management are presumably similar, our case provides a useful opportunity to review and rationalize the indications, route, dose, and efficacy of flap thrombolysis, of which there remains no universally accepted consensus [5]. We also propose our algorithm for the salvage of free flaps in head and neck reconstruction (Fig. 7).

\section{Indication}

The indications for flap thrombolysis vary in the literature (Ta- ble 1). Panchapakesan et al. [7] proposed that the criterion for using thrombolytic therapy was failure to re-establish satisfactory venous outflow despite restoring good arterial inflow. This is logical as it suggests the presence of significant intra-flap thrombosis obstructing venous outflow [1], and is adopted by other authors including Bui et al. [1], Rinker et al. [5], and Bonde et al. [8]. Other authors recognize late-explored flaps as an indication. Yii et al. [9] suggested that whereas thrombosis that is recognized early is often treated successfully with anastomotic revision alone, cases recognized or re-explored late (with a longer warm ischemic time) tend to have increased thrombus formation and "no-reflow phenomenon," requiring additional intervention such as thrombolysis. Similarly, Bui et al. [1] also recognized late thrombosis, as evidenced by extensive, established clots (usually white), as an indication. Venous thrombosis (as opposed to arterial) has also been identified as an indication, as proposed by Serletti et al. [10] and Casey et al. [3]. Serletti et al. suggest that this might be because venous thrombosis tends to be detected later, resulting in microcirculatory changes and a poorer response to anastomotic revision alone. Based on the same rationale, Chang et al. [11] routinely perform thrombolysis for all cases of venous thrombosis; in addition, they also perform thrombolysis for isolated arterial thrombosis if there is vi- 
sualized distal clot propagation from the perianastomotic area into the flap.

In our case, pedicle thrombosis was limited to the artery, and the cause was likely a technical issue resulting in thrombus formation at the anastomosis. This was dislodged distally by attempts at milking, into the branches of the flap artery (muscle branches and perforators), making the thrombi difficult to retrieve by Fogarty thrombectomy. Fogarty thrombectomy is indicated in extensive pedicle thrombosis which cannot be removed through simple extraction at the anastomotic site [12], but without propagation into the perforators of the flap, as thrombosis at this level is too distal for mechanical retrieval. Distal clot propagation (as described by Chang et al.) was the main indication for thrombolytic therapy [11]. Without thrombolysis, the revision of the arterial anastomosis alone would unlikely be successful as the clots would continue to obstruct vascular inflow, or propagate further distally and result in intra-flap thrombosis.

Hence, we suggest that the main indications for thrombolysis are (1) arterial thrombosis with evidence of distal clot propagation (as described by Chang et al.), (2) venous thrombosis with failure to restore venous outflow despite thrombectomy and reestablishment of arterial inflow (as this suggests the presence of intra-flap thrombosis), and (3) late thrombosis (as evidenced by extensive clots, usually white.) This is illustrated in our proposed algorithm (Fig. 7), which may be applied to both revision cases as well as primary surgery. This case also demonstrates that milking an arterial anastomosis (empty-refill test) to check for its patency should be avoided; instead, the arterial anastomosis may be partially opened and the clot removed by gentle manual extraction or Fogarty catheter if it is more distal [4].

\section{Route of administration}

Intra-arterial injection of thrombolytic agent remains the most common route of administration. This may be performed through a small arteriotomy in the main pedicle, through a side branch of the artery, or at the site of original arterial anastomosis $[1,7]$. Either way, the recipient artery (proximal to the injection site) and the draining vein(s) are clamped prior to injection, to allow the thrombolytic agent to remain in the flap circulation [1]. The agent is then allowed to drain through an open flap vein, to prevent its flow into the systemic circulation. In cases of end-to-side arterial anastomosis, the recipient artery distal to the anastomosis should also be clamped prior to injection to prevent systemic absorption [10]. In our case, injection was performed at the site of the original arterial anastomosis as this had already been taken down and provided an open lumen for easy access, avoiding the need for additional arteriotomy or side branch dissection.

The temporal order of thrombolysis versus revision of anastomosis also deserves discussion. In our case, injection was performed prior to revision of anastomosis; this is similar to the protocol suggested by Chang et al. [11] for arterial thrombosis with distal clot propagation. The presumable advantage is that thrombolysis begins earlier, giving the thrombus less time to expand or propagate. The reverse order has also been used, where the arterial anastomosis is first revised prior to thrombolysis $[4,5,8]$. This allows for easier assessment of flap perfusion following thrombolysis. Nonetheless, it is still possible to assess for response to treatment prior to re-establishing arterial inflow, by gauging the resistance to injection caused by the presence of thrombi. Serletti et al. [10] described their observation that a moderate amount of manual pressure was required on beginning the infusion of thrombolytic agent, but this gradually lessened and reached normal pressures as flap and venous blood color improved. A similar gradual reduction of injection pressures was also noted in our case, reflecting the successful removal of obstructing thrombi within the flap.

\section{Dose}

There remains no consensus as to the optimal dose of rTPA for flap thrombolysis, with varying practices ranging from as low as $2 \mathrm{mg}$ to as high as $50 \mathrm{mg}$ (Table 1). We adopt an initial dose of $10 \mathrm{mg}$ for multiple reasons: (1) this dose is similar to that used by Bui et al. (5-20 mg) and Yii et al. (15 mg), which are two of the largest cohorts studied to date (Table 1); (2) we believe that using a higher dose would be more effective in achieving successful thrombolysis than repeated lower doses of 2-2.5 mg; and (3) a dose of $10 \mathrm{mg}$ is an easy number to remember in a stressful situation of flap compromise. In our case, as resistance to injection of heparinized saline remained high after the first dose, we repeated a second dose of $10 \mathrm{mg}$, which resulted in reduction of resistance to injection.

The risk of systemic absorption and bleeding is also very low at such a dose. For comparison, the usual total dosage of rTPA to treat myocardial infarction is $100 \mathrm{mg}$ given intravenously; a dose of $150 \mathrm{mg}$ is associated with increased risk of intracranial bleeding [4]. In flap thrombolysis, most of the rTPA is flushed out through the open flap vein prior to venous anastomosis, and only a small proportion will end up in the systemic circulation. In addition, the half-life of rTPA is only 5 minutes, which means that there is only a very short time window in which there is an increased bleeding risk. While our patient did develop mild periorbital bruising on postoperative day 1 , this was likely due to the administration of intravenous heparin rather than intra-flap rTPA. 


\section{Efficacy}

Evidence supporting the use of flap thrombolysis in improving salvage rates remains limited (Table 1). Casey et al. [3] and Serletti et al. [10] reported excellent salvage rates of $100 \%$, though their sample size was small (11 and 5 patients, respectively), limited to use in venous thrombosis only, and there was no control group (without thrombolysis) for comparison. Rinker et al. [5] reported higher salvage rates in flaps receiving thrombolysis compared to those without ( $67 \%$ vs. $29 \%$, respectively), although this was not statistically significant. Other retrospective reviews also failed to demonstrate any statistically significant difference in salvage rates, with some reporting an even lower salvage rate with thrombolysis [7]. This could be explained by the fact that flaps requiring thrombolysis tend to be explored later and have more extensive thrombosis [7]. Further studies adjusting for time to exploration would be useful for more accurate analysis of efficacy. In our case, the flap was successfully "salvaged" with thrombolysis. Given the presence of multiple irretrievable thrombi within the flap, revision of arterial anastomosis alone would have been unlikely to achieve the same outcome, as it would only push the clots further distally and compromise flap perfusion. Successful salvage in our case was also likely contributed by the fact that thrombolysis was performed early, and so it is easier to dissolve the clot.

In conclusion, this case illustrates the successful use of rTPA in treating flap thrombosis during primary free flap reconstruction of a head and neck defect. It is important to regularly check flap perfusion even though it may be patent immediately following microvascular anastomosis, as pedicle thrombosis may occur most frequently in the first 24 hours and even intraoperatively. Intraoperative detection and anastomotic revision provide a better chance at flap salvage. If an arterial thrombus is identified, attempts at milking should be avoided to prevent distal clot propagation towards the flap. If there is propagation of clots into the flap, thrombolysis is indicated to restore perfusion and improve the chance of successful flap salvage.

\section{NOTES}

\section{Conflict of interest}

No potential conflict of interest relevant to this article was reported.

\section{Ethical approval}

The study was performed in accordance with the principles of the Declaration of Helsinki. Written informed consent was obtained.

\section{Patient consent}

The patient provided written informed consent for the publication and the use of his images.

\section{Author contribution}

Conceptualization: SL Zhang, HW Ng. Data curation, formal analysis, methodology: SL Zhang, HW Ng. Project administration, visualization: SL Zhang, HW Ng. Writing - original draft: SL Zhang. Writing - review \& editing: SL Zhang, HW Ng.

\section{ORCID}

Steven Liben Zhang https://orcid.org/0000-0001-6504-9970

Hui Wen Ng https://orcid.org/0000-0002-7661-2439

\section{REFERENCES}

1. Bui DT, Cordeiro PG, Hu QY, et al. Free flap reexploration: indications, treatment, and outcomes in 1193 free flaps. Plast Reconstr Surg 2007;119:2092-100.

2. Chiu YH, Chang DH, Perng CK. Vascular complications and free flap salvage in head and neck reconstructive surgery: analysis of 150 cases of reexploration. Ann Plast Surg 2017;78(3 Suppl 2):S83-8.

3. Casey WJ 3rd, Craft RO, Rebecca AM, et al. Intra-arterial tissue plasminogen activator: an effective adjunct following microsurgical venous thrombosis. Ann Plast Surg 2007; 59:520-5.

4. Hanasono MM, Butler CE. Prevention and treatment of thrombosis in microvascular surgery. J Reconstr Microsurg 2008;24:305-14.

5. Rinker BD, Stewart DH, Pu LL, et al. Role of recombinant tissue plasminogen activator in free flap salvage. J Reconstr Microsurg 2007;23:69-73.

6. Lipton HA, Jupiter JB. Streptokinase salvage of a free-tissue transfer: case report and review of the literature. Plast Reconstr Surg 1987;79:977-81.

7. Panchapakesan V, Addison P, Beausang E, et al. Role of thrombolysis in free-flap salvage. J Reconstr Microsurg 2003;19:523-30.

8. Bonde CT, Heslet L, Jansen E, et al. Salvage of free flaps after venous thrombosis: case report. Microsurgery 2004;24: 298-301.

9. Yii NW, Evans GR, Miller MJ, et al. Thrombolytic therapy: what is its role in free flap salvage? Ann Plast Surg 2001;46: 601-4.

10. Serletti JM, Moran SL, Orlando GS, et al. Urokinase protocol for free-flap salvage following prolonged venous thrombosis. Plast Reconstr Surg 1998;102:1947-53. 
11. Chang EI, Mehrara BJ, Festekjian JH, et al. Vascular complications and microvascular free flap salvage: the role of thrombolytic agents. Microsurgery 2011;31:505-9.
12. Hong KY, Chang LS, Chang H, et al. Direct thrombectomy as a salvage technique in free flap breast reconstruction. Microsurgery 2017;37:402-5. 